J. Japan. Assoc. Min.

Petr. Econ. Geol.

$82,189-202,1987$

\title{
Role of free volume in the viscous behavior of magma
}

\author{
Hiromitsu Taniguchi* and Tsutomu Murase** \\ *Department of Earth Sciences, Science Education Institute of \\ Osaka Prefecture, Karita 4-13-23, Sumiyoshiku, Osaka 558 \\ **Department of Physics, The Institute of Vocational Training, \\ 1960, Aihara, Sagamihara, Kanagawa 229
}

\begin{abstract}
In the present study, the effects of free volume on the viscous behavior of magmatic melts are discussed on the basis of free-volume theory. The most important conclusion is that the change of viscosity with temperature, pressure, and composition is related approximately to the change of free volume in the melts.

It has been found that an increase of temperature and mafic components induces an increase of free volume in magmatic melts, and it is well known that they also tend to cause a decrease of viscosity. The relation between free volume and viscosity is interpreted as a reflection of the greater ease of movement of constituent units in melts that have more interstitial space.

Pressure effects on viscosity are also interpreted as fundamentally based on the change of free volume. Melts having an abundance of free volume at $1 \mathrm{~atm}$ are depolymerized melts and show an increase of viscosity with pressure owing to a decrease of free volume. On the other hand, in polymerized melts having a small free volume at low pressures, the controlling process of viscous flow is not the change of free volume but making or breaking of bonds between constituent units of the melt. Sharma et al. (1979) suggested on the basis of Raman spectroscopy that the decrease of viscosity of polymerized melts at high pressures was caused by deformation of constituent unit accompanying the weakening of $\mathrm{Si}-\mathrm{O}-\mathrm{Si}$ bond. Our explanation of the behavior of polymerized melts is in harmony with their interpretation.
\end{abstract}

\section{Introduction}

A knowledge of molecular transport phenomena, such as viscosity and diffusion, is very important if one is to gain a better understanding of magmatic processes in the earth. Moreover, molecular-transport phenomena give information on the structure of magmatic silicate melts, since the phenomena are controlled strongly by the melt structure itself (Murase, 1981; Yoder, 1982). For instance, studies of the relations between viscosity, diffusion, and structure of magmatic silicate melts by Waff (1975), Kushiro (1976a, b, 1983) and Kushiro et al. (1976) are the typical examples of this approach. However, the results obtained by these and other workers (Velde and Kushiro, 1978; Virgo et al., 1980; Mysen et al., 1982 ; Seifert et al., 1982 ; Taniguchi, 1985) have only given informations on the constituent unit (3-dimensional network and silicate anion), and are obviously an inadequate model of melt structure for understanding the relation between the molecular transport and melt structure.

Generally speaking, liquid is composed of molecules (or constituent unit, solid-like part) and interstitial space (or free volume, gas-like part). Molecular transport phenomena are controlled by both parameters. In the case of some simple liquids, such as liquid Ar, flow unit (diffusion unit) coincides with the constituent 
unit, the Ar atom. On the other hand, in complex liquids, such as silicates and borates, the units responsible for flow behavior do not always coincide with the units at static state. In order to discuss the relation between melt structures and molecular transport, we must therefore have information on the constituent units, flow units, and free volume.

We shall discuss the flow behavior of magma mainly on the basis of the free volume theory of liquid. In particular we shall show that the viscosity-temperature-composition relations for magmas at 1 atm are controlled mainly by the free volume and that pressure effects (of less than $10 \mathrm{~kb}$ ) on viscosity is governed mainly by the free volume at $1 \mathrm{~atm}$.

\section{Theory}

Free volume in the temperature dependence of the viscosity

Many equations have been proposed to describe temperature-viscosity relation of liquids. For magmatic silicate melts, the Arrhenius type equation (Eq.1) and the Fulcher type equation (Eq. 2, Fulcher, 1925) have been used,

$$
\begin{aligned}
& \log \eta=\eta_{0}+E_{\eta} / 2.3 R T \\
& \log \eta=A+B /\left(T-T_{0}\right)
\end{aligned}
$$

where $\eta$ is viscosity, $T$ is absolute temperature, $\eta_{0}, A, B$ and $T_{0}$ are constants, $E_{\eta}$ is the apparent activation energy for viscous flow and $R$ is the gas constant.

The Arrhenius type equation describes very well the viscosity-temperature relations for stable liquids above their liquidus temperatures, but it fails to describe the relation for a super-cooled liquid. The activation energy $E_{\eta}$ calculated from Eq. 1 has been recognized to correspond to the height of energy barrier needed for the activation of the system, but the physical meaning of the constant $\eta_{0}$ has not been well defined. The Fulcher type equation reproduces more exactly the experimental values in the range between the stable liquid state and that of a super-cooled liquid, but the physical meaning of this equation is not clear. These two equations have, therefore, been considered insufficient for describing the flow behavior of liquids. Many efforts to find a more suitable equation have been done. The absolute rate theory (or significant-structure theory, Glasstone et al., 1941 ; Ree et al., 1964) and the free-volume theory (Cohen and Turnbull, 1959; Kumar, 1963) are representative. Both of these theories attach importance to the interstitial space in the liquids though the theoretical process and results are somewhat different.

In the present study, we will analyze the viscosity-composition, temperature and pressure relations for magmatic silicate melts based on the free volume theory by Cohen and Turnbull (1959) and Kumar (1963).

A hard-sphere model is assumed as the structural basis of liquids. It is also assumed that there is a random distribution of voids in liquids. Let one mole of the liquid correspond to $N$ flow units, of which $\mathrm{Ni}$ units are associated with free volume, $v i$. The total free volume per mole $(V f)$ is

$$
V f=\Sigma(N i \cdot v i)=\Sigma(N i \cdot n i \cdot v)
$$

assuming that $v i$ is an integral multiple ( $n i$ ) of the smallest unit $v$. The average free volume is

$$
\bar{v}=V f / N
$$

where $N$ is Avogadro's number. The void associated with a particular flow unit continually changes in size without involving any activation energy. Therefore the probability of being associated with a void of any size is the same for all the flow units. Then, the probability $[P(n i \cdot v)]$ of having a free volume $n i \cdot v$ is 


$$
\begin{aligned}
P(n i \cdot v) & =\exp (-n i \cdot v / \bar{v}) / \Sigma \exp (-n i \cdot v / \bar{v}) \\
& =\exp (-n i \cdot v / \bar{v})[1-\exp (-v / \bar{v})] .
\end{aligned}
$$

When the free volume is continually variable, $n i \cdot v$ is equal to $v i$ and the smallest unit $v$ may be written $d v$. Equation (5) then becomes

$$
P(d v)=\exp (-v i / \bar{v}) d v / v .
$$

Let the minimum size of the hole into which the flow unit moves be $v_{0}$; the probability of finding one of the holes with a volume $v_{0}$ or greater is

$$
P\left(v_{0}\right)=\int_{v_{0}}^{\infty} P(d v)=\exp \left(-v_{0} / \bar{v}\right) .
$$

The diffusion coefficient $(D)$ for a hard-sphere model can be expressed as

$$
D=\operatorname{gau} P\left(v_{0}\right)
$$

where $g$ is a geometrical factor, $a$ is the diameter of the flow unit, and $u$, the gas kinetic velocity, is

$$
\sqrt{(3 k T / m)}
$$

$m$ being the mass of the flow unit. On the other hand, using the Stokes-Einstein equation, the viscosity-diffusion coefficient relation for a liquid having spherical flow units may be written

$$
D=k T /(3 \pi a \eta)
$$

where $k$ is the Boltzmann constant and $T$ is absolute temperature. Combining Equations (7), (8), (9) and (10)

$$
\begin{aligned}
\eta / \sqrt{T} & =A \exp \left(v_{0} / \bar{v}\right) \\
& =A \exp \left[N v_{0} /\left(V_{T_{2}}-V_{T_{1}}\right)\right]
\end{aligned}
$$

$V_{T_{2}}$ being the molar volume of the substance at $T_{2} \mathrm{~K}$. At $T_{1} \mathrm{~K}$ the molar volume is $V_{T_{1}}$ and the number of holes is zero. The constant $A$ in Eq. 11 is

$$
\sqrt{m k} /\left(3 \sqrt{3} \pi g a^{2}\right) .
$$

According to Cohen and Turnbull (1959), the free volume associated with one flow unit may overlap that associated with another. To make a correction for this factor the term $v_{0}$ in Eq. 11 should be replaced by $\gamma \cdot v_{0}$ where $\gamma$ is a numerical constant having a value between 0.5 and 1. Therefore,

$$
\log \eta / \sqrt{T}=\log A+\gamma V_{0} \log e / V f
$$

where $V_{0}$ is the volume per mole of the flow units and $V f$, the molar free volume, is $V_{T_{2}}-$ $V_{T_{1}}$.

If we assume a linear relation between temperature and the volume of a liquid, we get a simplified equation from Eq. 12 like the equations by Cukierman et al. (1973) and Cranmer and Uhlmann (1981), that is

$$
\log \eta=A+0.5 \log T+B /\left(T-T_{0}\right)
$$

where $A, B$ and $T_{0}$ are constants. Equations (12) and (13) are the general form of the temperature-viscosity relation based on the free volume theory.

Free volume in the pressure dependence of the viscosity

Pressure effects on liquids have been treated theoretically by assuming the change of interstitial space in liquids. The representative theories for the effect are the significantstructure theory of Jhon et al. (1969) and the free-volume theory of Matheson (1966). Both theories assume that there is a sufficient interstitial space in liquids, and the space diminishes with increasing pressure. To apply the free volume theory to magmatic silicate melts, equation 12 can be rewritten at constant temperature

$$
\log \eta=A+B V_{0} / V f
$$

where $A$ and $B$ are constants, $V_{0}$ is molar volume of molecule in the melts, and $V f$ is molar free volume.

This equation is equivalent to the Doolittle equation (Doolittle, 1951 ; Doolittle and Doolittle, 1957) which describes the relation between 
viscosity and volume of liquid at 1 atm. If $A$ and $B$ are constants independent of temperature and pressure, we can calculate the viscos. ity at an arbitrary temperature and pressure using experimental results at 1 atm and compressibilities of liquid and molecule. If there is a sufficient free volume in the liquid, a pressure increase causes an initial decrease of free vol. ume as the $V_{0} / V f$ ratio decreases, and viscosity increases. Matheson (1966) showed that the calculated values based on the free volume theory agreed with the experimentals for $n$ hexane, n-octane, and other organic liquids. He mentioned, however, that the theory could not yield exact value for the liquids with small free volumes.

\section{Calculation of free volume}

The definition of free volume is the empty space between the constituent units in liquids. The methods (Nose, 1971) used to estimate this free volume experimentally can be divided into two types. One is an indirect method in which one assumes the equation relating the free volume to viscosity (e.g., Eq. 14), fits the experimental data of viscosity and volume and then calculates the free volume using constants of the equation. This indirect method is obviously not appropriate for the purpose of relating free volume to viscosity more exactly, because one must first assume the type of equation. The other is a direct method in which the definitions of free volume (Bondi, 1954 ; Nose, 1971) are

$$
V f_{0} \equiv V_{\iota}-V_{0}
$$

and

$$
V f_{s} \equiv V_{l}-V_{s}
$$

where $V_{l}$ and $V_{s}$ are the volumes of liquid and crystal corresponding to the liquid at temperature $T$ respectively, and $V_{0}$ is the volume of the liquid at $0 \mathrm{~K}$. According to the definition by Bondi (1954), $V f_{0}$ is the free volume as expansion volume and $V f_{s}$ is the free volume as excess volume. However, these two definitions entail problems. One is that the former definition neglects the volume change of molecules resulting from an increasing temperature. The other is that the application of the latter to the magma (liquid) is difficult, because the exact measurement of thermal expansion of polycrystalline materials, such as igneous rocks, is very difficult.

On the other hand, Simha and Boyer (1962) have defined the free volume at the glass transition temperature, $T_{g}$, in order to examine the relation between the glass transition and free volumes of high-polymer materials;

$$
V f \equiv\left(\alpha_{\ell}-\alpha_{g}\right) T_{g}
$$

where $\alpha_{\iota}$ and $\alpha_{g}$ are the coefficients of cubic expansion above $T_{g}$ and below $T_{g}$ respectively. Fig. 1 shows the relation between the volume of glass-forming melt and temperature. The volume of the melt with a free volume of 0 is $V_{0 l}$ : the volume of melt linearly extraporated from super-cooled liquid state to $0 \mathrm{~K}$ with the thermal expansion coefficient $\alpha_{l}$. This definition cannot be applicable to the high temperature range above $T_{\mathrm{g}}$. We need a new definition, therefore, which holds for all states of melt: glassy state, super-cooled liquid state and stable liquid state. In order to get a new definition of free volume, we make two assumptions. The first is that the volume of melt, the free volume of which is 0 , is $V_{0}$ in the same manner as the definition by Simha and Boyer (1962). The second is that the thermal expansion coefficient of constituent unit in melts at all temperatures is the same value as that of melt in glassy state. It is well known that the second assumption is established for organic and inorganic amorphous materials below liquidus (or melting) temperatures. In the present deffinition; it is assumed that the relation is also 


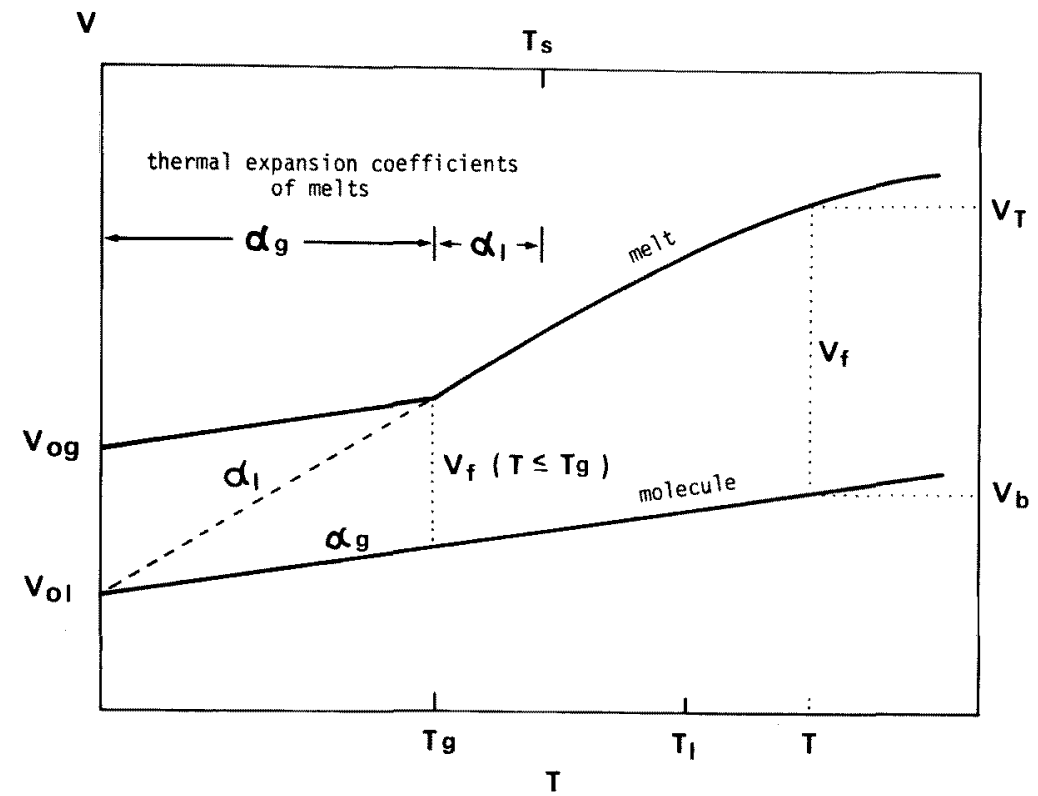

Fig. 1. Volume-temperature relations for melt and molecule in melts. Tg, glass transition tempera ture; $\mathrm{T}_{1}$, liquidus temperature; $\mathrm{T}$ s, softing temperature. For the other symbols, see the text.

applicable to the stable liquid state, i.e. to melts above their liquidus temperatures. This assumption may be supported by the fact that the constituent units in silicate melts at stable liquid state coincide with those in a glassy state (Riebling, 1968 ; Seifert et al., 1981).

The line starting at $V_{0 g}$ in Fig. 1 shows the volumetric change in a melt along the glassy state $\sim$ super-cooled liquid state $\sim$ stable liquid state. The lower straight line from $V_{0}$ indicates the volume change of constituent units (molecule) in the melt. The difference between the partial volume of constituent units in the melt $\left(V_{b}\right)$ and the total volume of the melt $\left(V_{T}\right)$ at temperature $(T)$ is the free volume. The volume fraction of free volume in the melt at $T$ $\geq T_{g}$ is

$$
\begin{aligned}
V f & \equiv\left(V_{T}-V_{b}\right) / V_{T} \\
& =1-D_{T}\left(1+T \alpha_{g}\right) /\left\{D_{T_{g}}\left(1+T_{g} \alpha_{l}\right)\right\} .
\end{aligned}
$$

At $T<T_{g}$

$$
V f=D_{T} \cdot T_{g} \cdot\left(\alpha_{1}-\alpha_{g}\right) /\left\{D_{T_{g}} \cdot\left(1+T_{g} \alpha_{1}\right)\right\}
$$

where $D_{T}$ and $D_{T_{s}}$ are densities of the melt at $T$ and $T_{g}$ respectively, $\alpha_{g}$ and $\alpha_{l}$ are respectively the cubic thermal expansion coefficients for the glassy and super-cooled liquid states near $T_{g}$. The free volume of the melt below $T_{g}$ is almost constant.

\section{Discussion}

Role of free volume in the viscosity-temperature-composition relation

Table 1 shows a comparison of the coefficients of correlation between experimental and calculated values using the Arrhenius type equation (Eq. 1) and free-volume type equation (Eq. 13). As can be seen in the Table 1 , the free volume-type equation yields better correlations. This result suggests that the free volume plays an important role in the viscous behavior of magma.

Fig. 2 shows the free volume-temperature relation for Columbia River basalt based on Eqs. 18 and 19. The free volume is almost 
Table 1. Comparison of the coefficients of correlation between experimental viscosity and calculated one

\begin{tabular}{lccccc}
\hline Composition & \multicolumn{2}{c}{ I } & A & F & A \\
& F & AT & & \\
\hline Di70An30 & 0.9985 & 0.9906 & 0.9950 & 0.9938 \\
Di64An36 & 0.9992 & 0.9983 & 0.9993 & 0.9978 \\
Di60An40 & 0.9982 & 0.9979 & 1.0000 & 0.9990 \\
Di55An45 & 0.9995 & 0.9905 & 0.9999 & 0.9999 \\
Di46.1An53.9 & 1.0000 & 0.9970 & 1.0000 & 0.9990 \\
GOB & 0.9921 & 0.9867 & 0.9893 & 0.9884 \\
CRB & 0.9995 & 0.9994 & 0.9999 & 0.9992 \\
MHA & 0.9998 & 0.9978 & 0.9996 & 0.9981 \\
NRO & 0.9985 & 0.9981 & $/$ & $/$ \\
\hline
\end{tabular}

I, temperature range includes below and above liquidus temperature $\left(\mathrm{T}_{1}\right) ; \mathbb{H}$, temperature range is above $T_{1} ; F$, the calculated values are based on the free-volume type equation ; $A$, the calculated values are based on the Arrhenius type equation. Di, diopside (mol.\%); An, anorthite; GOB, Galapagos olivine basalt; CRB, Columbia River basalt; MHA, Mount Hood andesite; NRO, Newberry rhyolite obsidian. Data sources for the calculation: volcanic rock composition (Murase and McBirney, 1973), diopside-anorthite (Taniguchi and Murase, submitted).

constant below the glass transition temperature and increases abruptly above $T_{g}$. The abrupt increase at $T_{g}$ is due to the dissolution of freeing of molecular movement, both translational and rotational, while the molecular movement in the melt is only vibrational below $T_{g}$.

Fig. 3 shows a linear relationship between viscosity and the reciprocal of free volume (volume fraction) for a melt of Columbia River basalt. Similar relations are found in the results for many magmatic silicate melts such as Mount Hood andesite and diopside compositions. This suggests that a Doolittle-type equation (Eq. 14) can be applied to magmatic silicate melts, and also indicates that the breaking or weakening of $\mathrm{Si}-\mathrm{O}$ bond are not necessary to the decrease of viscosity of magma with increasing temperature. The decrease of vis-

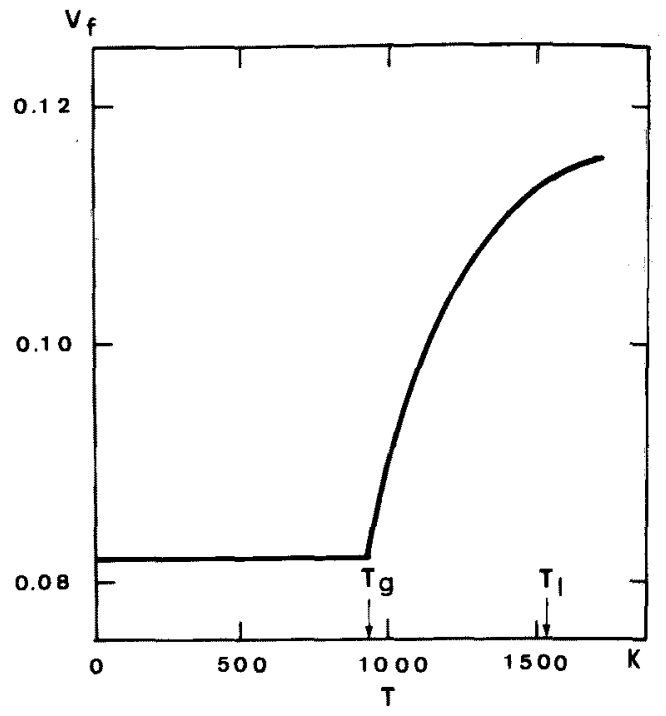

Fig. 2. Free volume (expressed as volume fraction)-temperature relation for Columbia River basalt. The calculation of free volume is based on Eqs. 18 and 19. Data sources: Murase and McBirney (1973) and Taniguchi and Murase (in prep.).

cosity with increasing temperature is due mainly to the increase of free volume, because the increase of free volume facilitates the move. ment of molecule in magma.

Fig. 4 shows the relation between the free volume defined by Simha and Boyer (1962) at $T_{g}$ and $\mathrm{NBO} / \mathrm{T}$ value (number of non-bridging oxygens per tetrahedral cations, $\mathrm{Si}, \mathrm{Al}$ and $\mathrm{Fe}^{3+}$ ) of melts. There are two reasons why we use the definition of free volume at $T_{g}$ by Simha and Boyer (1962) instead of the definition of the present study (Eqs. 18 and 19). One is the paucity of the data needed for the calculations based on the present definition. The other is that the melt at its glass transition temperature is in the corresponding state necessary for comparison of the characters of liquids. The free volume increases with an increase in NBO/ $\mathrm{T}$ as shown in the figure. Infra-red analyses of silicate melts (Taniguchi, 1985) suggest that the increase of the $\mathrm{NBO} / \mathrm{T}$ value corresponds to that of the silicate anion of high ionic charge 


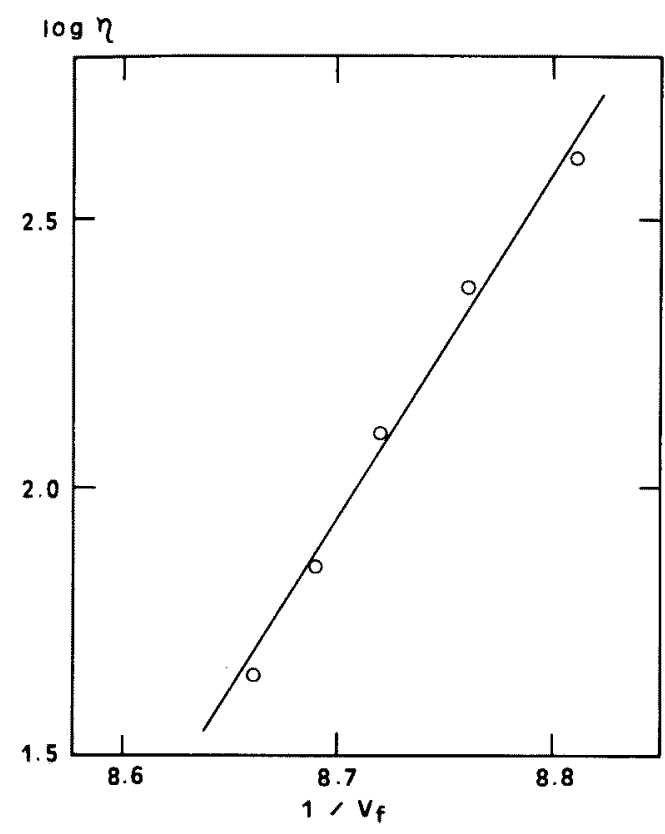

Fig. 3. Relation between viscosity and the reciprocal of free volume for Columbia River basalt. Data sources: Murase and McBir. ney (1973) and Taniguchi and Murase (in prep.).

per mass and the number of terminal bonding in melts, i.e., the increase of silicate anions of high $\mathrm{NBO} / \mathrm{Si}$ value. The increase in free volume may result from the vehement thermal movement of terminal bonding of constituent units, and the ionic repulsion between constituent units. The free volume in melts having the same NBO/T value depends on the cations of constituent units, namely, the free volume decreases with the following cation combinations.

$$
\mathrm{Si}+\mathrm{Al}+\mathrm{Fe}^{3+}, \mathrm{Si}+\mathrm{Al}>\mathrm{Si}
$$

The order of free volume at $T_{g}$ defined by Simha and Boyer (1962) for the melts of diopside, anorthite, basalt, andesite and other sili. cate compositions coincides with that of the free volume (Eq. 18) at an arbitrary temperature above the liquidus (Taniguchi and Murase, in prep.). This result may indicate that the

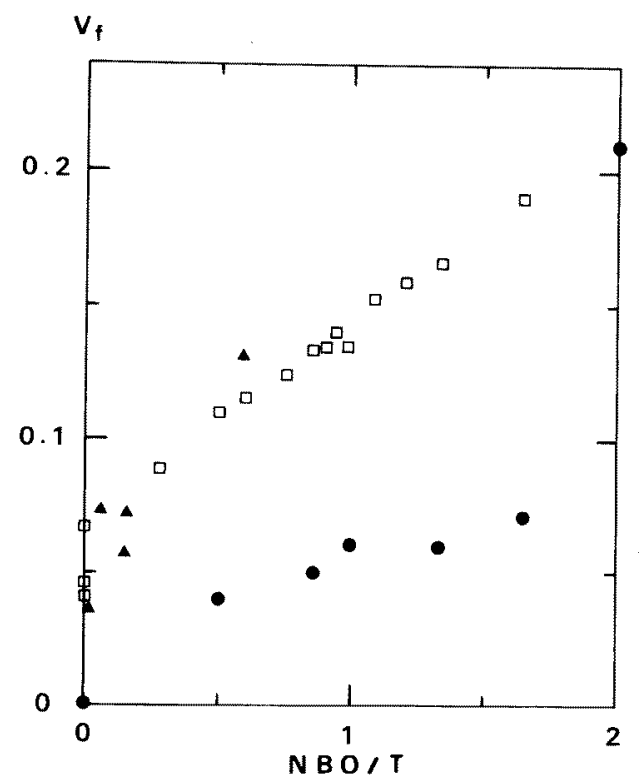

Fig. 4. Relation between the free volume at glass transition temperature (based on Eq. 17) and melt composition. $\mathrm{NBO} / \mathrm{T}$, number of non-bridging oxygen per network-forming ion ( $\mathrm{T}$ ) ; solid square, $\mathrm{T}=\mathrm{Si}+\mathrm{Al}+\mathrm{Fe}^{3+}$; open triangle, $\mathrm{Si}+\mathrm{Al}$; solid circle, $\mathrm{Si}$. Data sources: Suzuki and Abe (1981, quartz, $\left.\mathrm{SiO}_{2}-\mathrm{NaO}\right)$ and Taniguchi and Murase (submitted, diopside-anorthite), Taniguchi and Murase (in prep., basaltdacite, albite and jadeite).

order of free volume at $T_{g}$ agrees with that at the stable liquid state. Generally speaking, the viscosities of melts decrease with an increase in $\mathrm{NBO} / \mathrm{T}$ value. Thus it may be concluded that the compositional change of viscosity depends on the change of the free volume: the viscosity of magmatic silicate melts decreases with an increase in free volume, since molecules can move more easily if there is a sufficient free volume in the melts. By the same reasoning, it can be concluded that fully-polymerized melts ( $\mathrm{NBO} / \mathrm{T}=0$, but free volume $\neq 0$ ) which have intermediate cations $\left(\mathrm{Al}, \mathrm{Fe}^{3+}\right)$, such as jadeite and anorthite, have a lower viscosity than that of $\mathrm{SiO}_{2}$ melt in which the free volume is almost 0 .

These results suggest that the dependence 
of viscosity of magmatic silicate melts on composition and temperature is due mainly to the free volume of the melts.

Role of free volume in viscosity-pressure relations

Viscosities of liquids at high pressures have been measured for liquid hydro-carbons and mercury by Bridgman (1931), Griest et al. (1958), Lowitz et al. (1959) and McDuffie and Kelly (1964), and for liquid $\mathrm{B}_{2} \mathrm{O}_{3}$ by Sperry and Mackenzie (1968), and it was proved that these liquids show an increase in viscosity at high pressures. Bridgman (1931), Bett and Cappi (1965) and Horne and Johnson (1966) showed that the viscosity of liquid $\mathrm{H}_{2} \mathrm{O}$ decreased with increasing pressure up to $1.5 \mathrm{~kb}$ and increased above $1.5 \mathrm{~kb}$ below $30^{\circ} \mathrm{C}$. The decrease of viscosity of water has been considered to be due to the breaking of hydrogen bonding among $\mathrm{H}_{2} \mathrm{O}$ molecules. Viscosities of magmatic silicate melts at high pressures have been measured by Kushiro (1976a, b), Kushiro et al. (1976) and Scarfe et al. (1979). Their experimental results made it clear that the viscosity of depolymerized melts increases with increasing pressure, while that of polymerized melts decreases. Sharma et al. (1979) investigated the reason for a decrease of viscosity of jadeite melts at high pressures on the basis of Raman spectroscopy, and they ascribed the decrease to the increase of the proportion of constituent units having small $\mathrm{Si}-\mathrm{O}-\mathrm{Si}$ bond angles at high pressures.

As mentioned previously, if the decrease of volume of melts at high pressures is due to the decrease of free volume, then the viscosity should increase in accordance with Eq.14. Such liquids may be expected to have relatively large free volumes at $1 \mathrm{~atm}$. Fig. 5 shows the relation between $\Delta \log \eta / \Delta P$ (the coefficients of viscosity change with pressure over the range $1 \mathrm{~b}$ to about $10 \mathrm{~kb}$ ) and free volume at $1 \mathrm{~atm}$ and

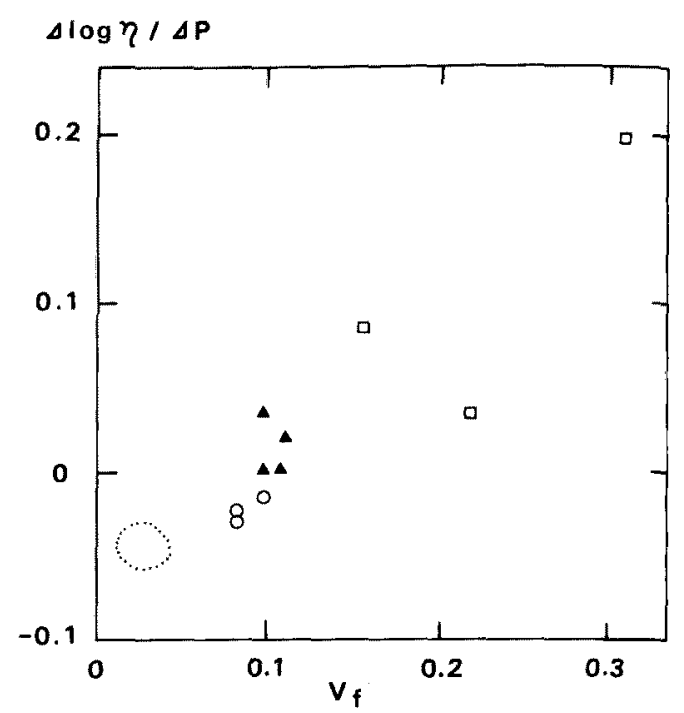

Fig. 5. Relation between the pressure dependence of viscosity and free volume of melts. Symbols indicate the type of viscosity change at a given high pressure range. Open square, the type of viscosityincrease; solid triangle, the type of constant or the type of decrease after initial increase; open circle and the area within the dotted circle, the type of decrease. For the data sources, see the text.

the temperature of the high pressure experiments. The viscosity data at high pressures are the experimental results by Sperry and Mackenzie (1968, $\mathrm{B}_{2} \mathrm{O}_{3}$ ), Kushiro et al. (1976), Fujii and Kushiro (1976, $\mathrm{Na}_{2} \mathrm{O} \cdot 3 \mathrm{SiO}_{2}$, basalt, andesite), Scarfe et al. (1979, $\mathrm{Na}_{2} \mathrm{O} \cdot 2 \mathrm{SiO}_{2}$, $\mathrm{Na}_{2} \mathrm{O} \cdot \mathrm{SiO}_{2}$, diopside) and Kushiro (1981, anorthite). The density data for calculating the free volume at $1 \mathrm{~atm}$ are quoted from the literature by Napolitano et al. $\left(1965, \mathrm{~B}_{2} \mathrm{O}_{3}\right)$, Shartsis et al. (1952, $\mathrm{Na}_{2} \mathrm{O} \cdot \times \mathrm{SiO}_{2}$ ), Daněk and Ličko (1981, NBS-710), Ličko and Daněk (1982, diopside) and Ogino and Nishiwaki (1976, anorthite). The data for thermal expansion in the glassy and super-cooled liquid state, and data for density in the liquid state of the other melts mentioned above are from Taniguchi and Murase (submitted). The data of fully polymerized melts such as jadeite, albite and 
$\mathrm{GeO}_{2}$ melts are not shown in the figure, because there are no correct data of density at $1 \mathrm{~atm}$, although there are viscosity values at high pressures (Kushiro, 1976a, b, 1978a, b). The data for jadeite and albite melts, however, may fall within the dotted circle based on the densities estimated by the method of Bottinga and Weill (1970). As can be seen in the figure, the melts having large free volumes at $1 \mathrm{~atm}$ have a tendency to increase in viscosity at high pressures. It is also obvious that the type of variation of viscosity with increasing pressure depends on the free volumes at 1 atm: the viscosity of the melts of high free volume increases, while that of low free volume decreases. The melts of intermediate free volume decrease in viscosity after an initial increase.

The viscosity increase of the melts having large free volumes may be interpreted as the decrease in the free volume with increasing pressures which leads to the difficulty of molecular movement in the melts. The initial increase of viscosity of the melts having intermediate free volume may also depend on the decrease of free volume. The rate of the decrease of free volume should decrease with increasing pressure because the repulsions among constituent units would increase. The additional increase in pressure may cause a decrease in volume of constituent units themselves instead of a free volume. Thus the idea that the main factor controlling the viscous behavior of melts is the free volume change seems to be inapplicable to the effect of pressure on the melts having small free volumes.

In order to interpret the pressure effect more exactly, we employ the hybrid theory by Macedo and Litovitz (1965). According to that theory, the viscosity of a liquid is controlled by the probability $(P e)$ of attaining sufficient energy to break bonds,

$$
P e \simeq \exp \left(-E v^{*} / R T\right)
$$

and by the probability $(P v)$ that there is sufficient local free volume for a jump of molecule to occur,

$$
P v \simeq \exp \left(-\gamma V_{0} / V f\right)
$$

where $E v^{*}$ is the activation energy at constant volume, $R$ is the gas constant, $V f$ is molar free volume, $V_{0}$ is molar volume of molecule, and $\gamma$ is a numerical factor needed to correct for the overlap of free volume and lies between 0.5 and 1. The relation between viscosity and the probabilities is given by the expression

$$
\begin{aligned}
& \eta \propto 1 /(P e \cdot P v) \\
& \quad=A \exp \left(E v^{*} / R T+\gamma V_{0} / V f\right)
\end{aligned}
$$

where $A$ varies with temperature but usually far less than does the exponential term. It is obvious that if the contribution of the term for the energy for breaking bonds is small enough to be neglected, Eq. 22 coincides with the Doolittle-type equation. On the other hand, if the contribution of the free-volume term is sufficiently small, the equation coincides with the Arrhenius type equation. Strictly speaking, however, the constant $A$ varies with tem perature, and the equation may be expressed with the following correction:

$$
\ln \eta=A+\ln T+E v^{*} / R T+\gamma V_{0} / V f
$$

Macedo and Litovitz (1965) demonstrated that Eq. 23 is applicable to many liquids, and they defined the parameter (Rev) to compare the contribution of the free volume term, $P v$, and of the term of energy to break bonds, $P e$, to the viscous behavior of liquids,

$$
\begin{aligned}
\operatorname{Rev} & =P e / P v \\
& =\exp \left\{\left(V_{0} / V f\right)-\left(E v^{*} / R T\right)\right\}
\end{aligned}
$$

where $\gamma$ is assumed to be unity.

In the case of liquids with large Rev values, the viscous behavior is dominated mainly by the breaking or recombination of bonds, while in the case of melts with small Rev values, it is 
Table 2. Some parameters for the discussions on the viscosity-pressure relation including the parameters based on the hybrid theory for some melts

\begin{tabular}{|c|c|c|c|c|c|c|c|c|}
\hline \multirow[t]{2}{*}{ Composition } & \multirow{2}{*}{$\begin{array}{l}\mathrm{T} \\
\mathrm{K}\end{array}$} & \multicolumn{2}{|c|}{$\Delta \log n / \Delta p$} & \multirow{2}{*}{$\begin{array}{l}\text { VET } \\
\text { Vol. } .8\end{array}$} & \multirow{2}{*}{$\begin{array}{r}\mathrm{Tg} \\
\mathrm{K}\end{array}$} & \multirow[t]{2}{*}{$\mathrm{v}_{\mathrm{f}} \mathrm{Tg}$} & \multirow{2}{*}{$\begin{array}{c}\mathrm{Ev}^{\star} \\
\mathrm{Keal} / \mathrm{mol}\end{array}$} & \multirow{2}{*}{$\begin{array}{l}\mathrm{Pe} / \mathrm{Pv} \\
\text { at } 1.5 \mathrm{Tg}\end{array}$} \\
\hline & & $\log$ & poise/Kb & & & & & \\
\hline $\mathrm{SiO} 2$ & 1 & & I & 1 & 1423 & 0.00 & 110 & $8 \times 10^{-10}$ \\
\hline $\mathrm{GeO} 2$ & 1698 & & -0.06 & 1 & 790 & 0.04 & I & 1 \\
\hline $\mathrm{Na} 20 \cdot 35102$ & 1448 & & -0.01 & 9.9 & 738 & 0.04 & 52 & $4 \times 10^{-6}$ \\
\hline CaAI2Si2OB & 1923 & & 0.00 & $(10.2)$ & 1115 & 0.07 & $(66)$ & $\left(6 \times 10^{-4}\right)$ \\
\hline $\mathrm{CaMgSi} 206$ & 1913 & & +0.03 & 22.3 & 993 & 0.21 & $(57)$ & $\left(10^{-4}\right)$ \\
\hline NBS -710 & 1 & & I & I & 830 & 0.18 & 36 & $5 \times 10^{-3}$ \\
\hline $\mathrm{B} 203$ & 789 & & +0.20 & 31.0 & 534 & 0.34 & 13 & $4 \times 10^{-1}$ \\
\hline
\end{tabular}

For the abbreviations, see the text. Data sources (viscosity, density) for the calculations: $\mathrm{SiO}_{2}$ (Bacon et al., 1960), $\mathrm{GeO}_{2}$ (Kushiro, 1978a), $\mathrm{Na}_{2} \mathrm{O}_{3} \mathrm{SiO}_{2}$ (Morey, 1938; Shartsis et al., 1952 ; Kushiro, 1976b), anorthite (Cukierman and Uhlmann, 1973; Ogino and Nishiwaki, 1976; Scarfe et al., 1983; Kushiro, 1981; Taniguchi and Murase, submitted), diopside (Ličko and Daněk, 1982; Scarfe et al., 1983; Taniguchi and Murase, submitted), NBS-710 (nominal values, Murase and McBirney, 1973; Dan èk and Ličko, 1981). Thermal expansion data depend on Taniguchi and Murase (submitted).

mainly dominated by the change of free vol. ume.

Table 2 shows the calculated results based on hybrid theory, and free volumes for some melts. Except for $\mathrm{SiO}_{2}$ and NBS-710, the melts are arranged in the table in accordance with the rate of change of viscosity with pressure $(\Delta \log \eta / \Delta P)$, the melts of lower order having a larger ratio. The bracketed values indicate that the accuracy is not satisfactory, since there are few data. The ratio tends to increase with the increase of free volume at the temperatures at which high-pressure measurements were made ( $\left.V f_{T}, \mathrm{Eq} .18\right)$ and the free volume at $T_{g}\left(V f_{T_{g}}\right.$, Eq. 17). The activation energy $\left(E v^{*}\right)$ at constant volume has a tendency to decrease with the increase of free volume.

The activation energy of $\mathrm{SiO}_{2}$ melt $\left(E v^{*} \sim\right.$ $110 \mathrm{kcal} / \mathrm{mol}$ ) is equal to the bonding energy of $\mathrm{Si}-\mathrm{O}$ bond $\left(E_{\mathrm{S} i-\mathrm{O}}-106 \mathrm{kcal} / \mathrm{mol}\right)$ within experimental error. This result may suggest that an $\mathrm{SiO}_{2}$ melt preserves a three-dimentional net- work structure at high temperatures, and that the mechanism of viscous flow is controlled mainly by the breaking of $\mathrm{Si}-\mathrm{O}$ bond. On the other hand, the activation energy of $\mathrm{B}_{2} \mathrm{O}_{3}$ melt $(\sim 13 \mathrm{kcal} / \mathrm{mol})$ is notedly smaller than the energy of $\mathrm{B}-\mathrm{O}$ bonds $(\sim 89$ or $119 \mathrm{kcal} / \mathrm{mol}$, Sun, 1947). According to Sperry and Mackenzie (1968), the structure of $\mathrm{B}_{2} \mathrm{O}_{3}$ melt at lower temperatures is a two-dimensional network. The network is destroyed and changes to discrete $\mathrm{B}_{2} \mathrm{O}_{3}$ units at higher temperatures. $\mathrm{B}_{2} \mathrm{O}_{3}$ melt at high temperatures is composed of small $\mathrm{B}_{2} \mathrm{O}_{3}$ units and it has an abundance of free volumes. Viscous flow may therefore occur without breaking $\mathrm{B}-\mathrm{O}$ bonds. This may account for the small activation energy.

The activation energy of the other silicate melts in the table are obviously lower than Si$O$ bonding energy. This may be related to two facts; the presence of many bonds having lower bonding energy than $\mathrm{Si}-\mathrm{O}$ bond and the presence of abundant free volumes. 
Macedo and Litovitz (1965) have expected that the $\mathrm{Pe} / \mathrm{Pv}$ ratio of $\mathrm{GeO}_{2}$ melt is very small, as it is in $\mathrm{SiO}_{2}$ melts, because of their similarity in physical and chemical properties. As shown in Table 2, the $P e / P v$ ratio increases with increasing $\Delta \log \eta / \Delta P$ ratio. In other words, the melts for which viscosity increases at high pressures (i.e. depolymerized melts) are the melts in which the main factor controlling viscous flow is the change of free volume, and in the case of the melts that show a decrease of viscosity (i.e. polymerized melt) the main controlling factor is breaking of bonds. This conclusion is in harmony with the conclusion obtained from the free volume- $\Delta \log \eta / \Delta P$ relation mentioned previously.

Consequently, the viscosity decrease in polymerized silicate melts at high pressures is probably due to the decrease of $\mathrm{Si}-\mathrm{O}$ bond angle accompanied by weakening of the bond as deduced by Sharma et al. (1979) on the basis of Raman spectroscopy.

\section{Summary}

We have discussed the relation between viscous behavior of magmatic silicate melts and their melt structure.

The main results are as follows:

(1) The variation of viscosity of magmatic silicate melts with temperature and composition depends mainly on the change of free volume in the melts. The free volume increases with increasing temperature and with a decrease in the proportions of felsic components, so that viscosity decreases because of a greater ease of molecular transport with increasing temperature and decreasing felsic components.

(2) The pressure effect on the viscosity of magmatic silicate melts in the relatively lower pressure range is related to the free volume at $1 \mathrm{~atm}$ and at temperatures where high pressure measurements have been made. If the melts have sufficient free volume, the decrease of volume is mainly due to the decrease of free volume and their viscosity increases because molecular transport is more difficult. In the case of melts having moderately small free volumes, pressure may increase ionic repulsion between constituent units, and thus the rate of decrease of free volume and increase of viscosity may be diminished. In the case of melts with very small free volumes, the decrease of volume with increasing pressure may not be accomplished solely by a decrease of free volume, but may be accompanied by deformation of constituent units. The main factor controlling their behavior should be the breaking of bond among constituent units. The idea that the decrease of viscosity at high pressures is due to weakening of the $\mathrm{Si-O}-\mathrm{Si}$ bond is in accord with the relations mentioned above.

Even though, we have found important insights into the relations between viscous behavior and the structure of magmatic silicate melt, there are still a number of unclear points. In order to resolve them, a theory must be developed to describe the viscous behavior of complex liquids, such as magmatic silicates, and many more precise measurements of physical properties at $1 \mathrm{~atm}$ and at high pressures are needed. Determinations of the equations of state for magmatic silicate melts are especially important.

Acknowledgements: The authors are indepted to Prof. A.R. McBirney of the University of Oregon for his constructive comments and critical reading of the early draft of the manuscript. One of the authors (H.T.) thanks Dr. I. Muroi and Mr. K. Ochiai for their kindfull encouragements and suggestions. A part of expense of this study was defrayed by the Grant for Scientific Research (1984, No.59540531) from the Ministry of Education, Science and 
Culture of Japan.

\section{References}

Bacon, J.F., Hasapis, A.A. and Wholly, J.W.Jr. (1960), Viscosity and density of molten silica and high silica content glasses. Phys. Chem. Glasses, 1, 90-98.

Bett, K.E. and Cappi, J.B. (1965), Effect of pressure on the viscosity of water. Nature, 207, 620621.

Bondi, A. (1954), Free volumes and free rotation in simple liquids and liquid saturated hydrocarbons. J. Phys. Chem., 58, 929-939.

Bottinga, Y. and Weil, D.F. (1970), Densities of liquid silicate systems calculated from partial molar volumes of oxide components. Amer. J. Sci., 269, 169-182.

Bridgman, P.W. (1931), The physics of high pressure. P. 398, Dover Publications, INC., New York.

Cohen, M.H. and Turnbull, D. (1959), Molecular transport in liquids and glasses. J. Chem. Phys., 31, 1164-1169.

Cranmer, D. and Uhlmann, D.R. (1981), Viscosities in the system albite-anorthite. $J$. Geophys. Res., 86, 7951-7956.

Cukierman, M., Lane, J.W. and Uhlmann, D.R. (1973), High-temperature flow behavior of glass-forming liquids: A free-volume interpretation. J. Chem. Phys., 59, 3639-3644.

Cukierman, M. and Uhlmann, D.R. (1973), Viscosity of liquid anorthite. J. Geophys. Res., 78, 4920-4923.

Daněk, V. and Ličko, T. (1981), Zariadenie na meranie fuzikalno-chemickych valstnosti kyslicnikovych tavenin. Silikaty, 25, 153-163.

Doolittle, A.K. (1951), Studies in Newtonian flow. II. The dependence of the viscosity of liquids on free-space. J. Appl. Phys., 22, 1471-1475.

Doolittle, A.K. and Doolittle, D.B. (1957), Studies in Newtonian flow. V. Further verification of the free-space viscosity equation. $J . A p p l$. Phys., 28, 901-905.

Fujii, T. and Kushiro, I. (1977), Density, viscosity, and compressibility of basaltic liquid at high pressures. Carnegie Inst. Washington Year Book, 76, 419-424.

Fulcher, G.S. (1925), Analysis of recent measurements of the viscosity of glasses. J. Amer. Ceram. Soc., 8, 339-355.

Glasstone, S., Laidler, K.J. and Eyring, H. (1941), The theory of rate process. P. 496-573, McGraw-Hill Book Co., New York, (Japanese translation).

Griest, E.M., Webb, W. and Schiessler, R.W. (1958), Effect of pressure on viscosity of higher hydro. carbons and their mixtures. J. Chem. Phys., 29, 711-720.

Horne, R.A. and Johnson, D.S. (1966), The viscosity of water under pressure. J. Phys. Chem., 70, 2182-2190.

Jhon, M.S., Klotz, W.L. and Eyring, H. (1969), Theoretical calculation of the pressure dependence of liquid hydrocarbon viscosity. $J$. Chem. Phys., 44, 695-699.

Kumar, S. (1963), Viscosity and free volume of fused borates and silicates. Phys. Chem. Glasses, 4, 106-111.

Kushiro, I. (1976a), Changes in viscosity and structure of melt of $\mathrm{NaAlSi}_{2} \mathrm{O}_{6}$ composition at high pressures. J. Geophys. Res., 81, 6347-6350.

Kushiro, I. (1976b), Decrease in viscosity of some synthetic silicate melts at high pressures. Carnegie Inst. Washington Year Book, 75, 611614.

Kushiro, I. (1978a), Viscosity change of $\mathrm{GeO}_{2}$ melt. Carnegie Inst. Washington Year Book, 77, 672674.

Kushiro, I. (1978b), Viscosity and structural changes of albite $\left(\mathrm{NaAlSi}_{3} \mathrm{O}_{8}\right)$ melt at high pressures. Earth Planet. Sci. Lett., 41, 87-90.

Kushiro, I. (1981), Change in viscosity with pressure of melts in the $\mathrm{CaO}-\mathrm{Al}_{2} \mathrm{O}_{3}-\mathrm{SiO}_{2}$. Carnegie Inst. Washington Year Book, 80, 339-341.

Kushiro, 1. (1983), Effect of pressure on the diffusivity of network-forming cations in melts of jadeitic compositions. Geochim. Cosmochim. Acta, 47, 1415-1422.

Kushiro, I., Yoder, H.S.Jr., and Mysen, B.O. (1976), Viscosities of basalt and andesite melts at high pressures. J. Geophys. Res., 81, 63516356.

Ličko, T. and Daněk, V. (1982), Densities of melts in the system $\mathrm{CaSiO}_{3}-\mathrm{CaMgSi}_{2} \mathrm{O}_{6}$ $\mathrm{Ca}_{2} \mathrm{MgSi}_{2} \mathrm{O}_{7}$. Phys. Chem. Glasses, 23, 67-71.

Lowitz, D.A., Spencer, J.W., Webb, W. and Schiessler, R.W. (1959), Temperature-pressure-structure effects on the viscosity of several higher hydrocarbons. J. Chem. Phys., 30, 73-83.

Macedo, P.B. and Litovitz, T.A. (1965), On the relative roles of free volume and activation energy in the viscosity of liquids. J. Chem. Phys., 42, 245-256.

Matheson, A.J. (1966), Role of free volume in the pressure dependence of the viscosity, $J$. Chem. Phys., 44, 695-699.

Mcduffie, G.E.Jr. and Kelly, M.V. (1964), Effect of 
pressure on the viscosity and dielectric relaxation time in glycerol. J. Chem. Phys, 41, 2666-2670.

Morey, G.W. (1938), The properties of glass. PP. 561, Reinhold Publishing Corporation, New York.

Murase, T. (1981), Thermophysical properties of some magmatic silicate liquids. Bull. Volcanol. Soc. Japan, Ser 2, 26, 161-185 (in Japanese).

Murase, T. and McBirney, A.R. (1973), Properties of some common igneous rocks and their melts at high temperatures. Geol. Soc. Amer. Bull., 84, 3563-3592.

Mysen, B.O., Finger, L.W., Virgo, D. and Seifert, F. A. (1982), Curve-fitting of Raman spectra of silicate glasses. Amer. Mineral., 67, 686-695.

Napolitano, A., Macedo, P.B. and Hawkins, E.G. (1965), Viscosity and density of boron trioxide. J. Amer. Ceram. Soc., 48, 613-616.

Nose, T. (1971), Glass transition of Polymer. Nihon gomu Kyoukaishi, 44, 961-972 (in Japanese).

Ogino, K. and Nishiwaki, J. (1976), Density and electrical conductivity of the slag in the system $\mathrm{CaO}-\mathrm{SiO}_{2}-\mathrm{Al}_{2} \mathrm{O}_{3}$. Annulal meeting of Molten Salt Committee, Abstract, 31-32 (in Japanese).

Ree, T.S., Ree, T. and Eyring, H. (1964), Significant structure theory of transport phenomena. $J$. Phys. Chem., 68, 3262-3267.

Riebling, E.F. (1968), Structural similarities between a glass and its melt. J. Amer. Ceram. Soc., 51, 143-149.

Scarfe, C.M., Mysen, B.O. and Virgo, D. (1979), Changes in viscosity and density of melts of sodium disilicate, sodium metasilicate, and diopside composition with pressure. Camegie Inst. Washington Year Book, 78, 547-551.

Scarfe, C.M., Cronin, D.J., Wenzel, J.T. and Kauffman, D.A. (1983), Viscosity-temperature relationships at $1 \mathrm{~atm}$ in the system diopsideanorthite. Amer. Mineral., 68, 1083-1088.

Seifert, F.A., Mysen, B.O. and Virgo, D. (1981), Structural similarlity of glasses and melts relevant to petrological processes. Geochim. Cosmochim. Acta, 45, 1879-1884.

Seifert, F.A., Mysen, B.O. and Virgo, D. (1982), Three-dimensional network structure of quenched melts (glass) in the system $\mathrm{SiO}_{2}-$ $\mathrm{MgAl}_{2} \mathrm{O}_{4}$. Amer. Mineral., 67, 696-717.

Sharma, S.K., Virgo, D. and Mysen, B.O. (1979), Raman study of the coordination of aluminum in jadeite melts as a function of pressure. Amer. Mineral., 64, 779-787.

Shartsis, L., Spinner, S. and Capps, W. (1952), Density, expansivity, and viscosity of molten alkali silicates. J. Amer. Ceram. Soc, 35, 155160.

Simha, R. and Boyer, R.F. (1962), General relation involving the glass temperature and coefficients of expansion of polymers. $J$. Chem. Phys., 37, 1003-1007.

Sperry, L.L. and Mackenzie, J.D. (1968), Pressure dependence of viscosity of $\mathrm{B}_{2} \mathrm{O}_{3}$. Phys. Chem. Glasses, 9, 91-95.

Sun, K.H. (1947), Fundamental condition of glass formation. J. Amer. Ceram. Soc., 30, 277-281.

Suzuki, S. and Abe, Y. (1981), The free volume of some oxide glasses at the transition tempera. ture. J. Non-crystalline Solids, 43, 141-143.

Taniguchi, H. (1985), Infra-red spectroscopic study on the silicate anionic structures of some magmatic silicate melts. Tscherm. Mineral. Petrogr. Mitt., 34, 117-130.

Velde, B. and Kushiro, I. (1978), Structure of sodium alumino-silicate melts quenched at high pressures; infrared and aluminum $\mathrm{K}$ radiation data. Earth Planet. Sci. Lett., 40, 137-140.

Virgo, D., Mysen, B.O. and Kushiro, I. (1980), Anionic constitution of 1-atmosphere silicate melts: Implications for the structure of igneous melts. Science, 208, 1371-1373.

Waff, H.S. (1975), Pressure-induced coordination changes in magmatic liquids. Geophys. Res. Lett., 2, 193-196.

Yoder, H.S.Jr. (1982), Experimental methods for determination of transport properties of magma. Phys. Chem. Earth, 13-14, 375-408. 
マグマの粘性流動における自由体積の役割

谷口宏充・村瀬 勉

温度や組成を変克たとき，マグマ中の自由体積はどのように变化し，その変化はマグマの粘性流動に対 していかなる影響を及ぼすのかを険討した。その結果，温度が上昇するはど，また，マグマ中の1個の網 目形成イオンに配位する非架橋酸素数が増加（～塩基性成分が增加）するほど自由体積は増大することが 明らかにされた。このことがマグマ中に就る分子運動を容易にし，粘性の低下をもたらするのと考えた。

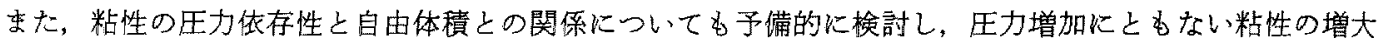
するメルトは相対的に自由体積が多く,減少するすのは自由体積の少ないメルトであることが示唆された。 